\title{
PART I. Components Impeding Insurability of Hazardous Waste Facilities and Approaches to Combat Them
}

by Baruch Berliner*

\section{Introduction}

No community of people can live without restrictions called rules of law. Restrictions determine the individual's degree of freedom. The restrictions characterizing social relationships include restrictions in every branch of economic activity. These show typical exogenous and endogenous initial and/or boundary conditions.

Sometimes, due to conflict of interest, such conditions may be changed to a degree that all activity dies out. Such a dramatic development usually occurs unintentionally and unexpectedly because reactions of other interested parties are miscalculated.

In an insurance branch, for instance, activity dies out when insurance coverage becomes unavailable, i.e. when all risks in that branch become subjectively uninsurable for all professional risk carriers.

How available is insurance coverage for hazardous waste risks in the USA?

In a report to the Congress on "Hazardous Waste Issues Surrounding Insurance Availability," the United States General Accounting Office (GAO) stated in October 1987 (1):

"Pollution liability insurance continues to be generally unavailable. Although more than 100,000 companies generate, handle, or dispose of hazardous substances, few of them have insurance for pollution risks" and "only one insurance organization is actively

${ }^{*}$ Swiss Reinsurance Company, Zurich. 
marketing pollution insurance. A few hundred companies are insured under its policies. The maximum annual coverage that can be purchased is $\$ 12.5$ million. Several other insurance organizations provide limited coverage pollution risk insurance.

We can conclude that insurance availability for hazardous waste risks is very restricted in the USA compared to cover needs. Hazardous waste risks are not very attractive to insurers. They have drifted out of the subjective domain of insurability for most of those professional risk carriers who were once prepared to cover them, mainly due to changes in exogenous conditions which altered the hazardous waste risks substantially and badly influenced their insurability.

Before we turn to the characteristics of waste disposal risks which render insurability difficult and how these difficulties may be mitigated, let us turn to the criteria of insurability as a basis for the analysis.

\section{The criteria of insurability}

An analysis of the insurability of risks in a certain branch should be based neither on the objects insured nor on the opinion of all risk carriers and risk owners, but only on the opinion of the professional risk carriers who insure risks in that branch (2).

We follow a pragmatic approach by basing insurability on the opinion of professional risk carriers. A risk is subjectively insurable for a risk carrier if he is prepared to cover it. If he covers, for example, an underrated risk, the risk is subjectively insurable for him, even if he should not be covering it at all.

The following nine criteria must be evaluated by a professional risk carrier in respect of each risk (3):

a) Randomness (of the loss occurrence)

b) Maximum possible loss

c) Average loss amount upon occurrence

d) Average period of time between two loss occurrences (loss frequency)

e) Insurance premium

f) Moral hazard

g) Public policy

h) Legal restriction

i) Cover limits

These nine criteria form a concise and nearly complete system, i.e. in nearly all practical cases they determine unequivocally for each professional risk carrier whether a risk is subjectively insurable for him or not.

If a criterion confirms the insurability of a risk, we say that it is satisfied. The criteria are not independent of each other. Most of them contain subjective as well as objective aspects.

If at last one criterion is not satisfied for a risk carrier, then the respective risk is subjectively uninsurable.

The subjective domain of uninsurability consists for a professional risk carrier of the set of all subjectively uninsurable risks in the lines of business in which he is underwriting or would underwrite in principle. 
The subjective domain of insurability which was mentioned in the introduction is complementary to the domain of subjective uninsurability and consists of the set of all subjectively insurable risks.

The objective domain of insurability is the intersection of all subjective domains of insurability, i.e. it consists of the set of all those risks which are subjectively insurable for all professional risk carriers. A risk lying in the objective domain of insurability is objectively insurable.

The intersection of all subjective domains of uninsurability is the objective domain of uninsurability. It is not complementary to the objective domain of insurability. Between the two domains lies an area of separation consisting of all risks that are for some professional risk carriers subjectively insurable and for others not.

The criteria of insurability can be quantified and interpreted in a geometric model as dimensions of insurability. To each risk a point can be assigned in a nine-dimensional Euclidean space.

The dimensions of insurability can be plotted in such a way that the objective domain of insurability is surrounded by the area of separation which is in turn surrounded by the domain of uninsurability.

A degree of insurability can be defined which allows us to develop a strategy of selecting the "best" risks out of a set of offers for coverage of insurable risks (4).

Keeping such a strategy in mind, it is important to make hazardous waste risks not only insurable again, but also attractive in comparison to risks from other branches that are "competing" for the available insurance capacities.

If a risk drifts out of the subjective domain of insurability for one professional risk carrier after another, it moves from the area of separation more and more towards the objective domain of uninsurability, becoming less and less attractive for insurance. For risks in the objective domain of uninsurability no insurance availability exists.

Insurance availability can decrease for a risk in three ways:

a) A risk may remain insurable in principle for a professional risk carrier, but other risks may become more attractive for him and fit better into his strategy. He may then reduce the capacity that he allocates for that risk.

b) The boundary lines of a risk carrier's subjective domain of insurability change in time. Although the mapping risk point does not change if the risk itself remains unchanged, the same point may fall outside an increasing number of subjective domains of insurability in the course of time due to exogenous factors involving the risk directly or indirectly.

Example: Better information on a risk may cause professional risk carriers to avoid the coverage of that risk by changing their subjective domains of insurability.

c) Endogenous or exogenous influence may change the risk itself and correspond to another point closer to or in the objective domain of insurability.

Insurance availability for hazardous waste risks decreased in the USA in the first place due to the third reason, and the first step to move them in the direction of the objective domain of insurability must therefore be to change the risks themselves accordingly. How to make them more attractive for capacity disposal, once they are insurable in principle, is the next step. 


\section{Endogenous components of hazardous waste risks which impede insurability and possible measures to fight them}

Endogenous components are risk-inherent components. One risk-inherent component that characterizes every risk is an element of unpredictability. Every risk premium must therefore contain a safety or fluctuation loading (3). A professional risk carrier must take into account two types of safety loadings, one for the uncertainty in the estimation of the expected total loss and the other as a compensation for covering the hazards inherent in the risk (3). Both components may heavily impede the insurability of hazardous waste risks.

The hazards inherent in waste risks are of a catastrophic nature and the fluctuations are characterized by large standard deviations. Consequently, this component of the safety loading significantly raises the price for coverage of hazardous waste risks.

The other safety loading component, the uncertainty in the estimation of the expected total loss, originates from lack of knowledge about the risk and specifies the extent of incalculability and guessing about the risk's correct pure risk premium.

In case of claims, lack of knowledge can lead to uncertainty about whether or not the insured or his insurers are liable for indemnification.

The uncertainty about the liable party arises especially in cases of gradual pollution caused by waste deposits and includes in the first place the time element. It is usually very difficult

a) to pinpoint the moment when pollution started,

b) to determine for how long it went on,

c) to specify the intensity of pollution in different time intervals, and

d) to specify, in case of huge waste deposits used by different "waste producers," whose waste actually polluted the water, soil and/or air respectively.

Finally, uncertainty often exists on whether or not a specific pollution adversely affected the health or property of claimants. The connection between cause and effect is not always clear.

The two components of safety loading must take all the elements of risk and uncertainty that were described above and their potential influence on the technical results, the reserving and accounting of the professional risk carrier into consideration. They therefore make the insurance coverage of waste risks very expensive, possibly too expensive for companies looking for insurance coverage.

The insurability criterion "insurance premium" is then not satisfied.

Additional entrants to a huge waste deposit increase the probability that the other companies will be considered liable in case of a pollution event due to uncertainty about whose waste triggered pollution. For the insurers of companies participating in a waste deposit, newcomers increase the "risk of contagion," thus reducing the degree of randomness. This effect may make the criterion of "randomness" unsatisfied (3).

The possibility that a waste producer and his insurers might be penalized for pollution caused by other waste producers contradicts the insurance principle of fairness, is inconsistent with the insurability criterion of "public policy" (3) and should be eliminated.

Availability of coverage for hazardous waste risks could be immensely increased if insurers would in future only cover companies which use their own waste deposits and impose on them an obligation to guard their deposits to avoid the storage of foreign waste in 
them. Such a measure should make the criterion "randomness" satisfied and eliminate the above-mentioned component of unfairness that is inconsistent with the criterion of "public policy." It should moreover reduce the uncertainty about the waste deposits and allow for a reduction of the "insurance premium."

The criterion of "cover limits" which includes clauses, restrictions, exclusions, and the like is a key to changing risks to a level of insurability. This criterion can reduce risks to partial risks and move them into the domain of subjective insurability. Partial risks are defined as risks in themselves. Thus, different parts or percentages of a risk are considered to be different risks. We met the criterion of "cover limits" in a first approach by our advice to exclude waste deposits used by several waste producers from coverage in future. It is important that the "cover limits" be worded very clearly, allowing no room for misinterpretation.

Since the uncertainty about the liable party inherent in cases of gradual pollution is very difficult to reduce substantially, we recommend that gradual pollution be excluded from coverage in a first step back to insurability of hazardous waste facilities as long as sufficient capacity has not yet been found for sudden and accidental pollution covers.

Since a great need for coverage against gradual pollution exists, great efforts should be made to create insurance capacity for this risk.

No effort should be spared in implementing these further steps:

a) to fix the time when gradual pollution began as precisely as possible,

b) to distribute liabilities among the insurers who cover the same facility as fairly as possible,

c) to prove the connection (and not only a vague possibility of a connection) between cause (gradual pollution) and effect (impaired health of persons claiming for indemnification,

d) to award affected persons a fair - however by no means an exaggerated - compensation,

e) to reduce additional costs to a minimum.

We are trying to describe here how the confidence of commercial insurers could be improved by exogenous measures, so that they may be willing to cover risks lying at the limits of insurability. Moreover, such measures reduce the uncertainty about hazardous waste disposal risks and contribute to the possibility of reducing the risk premiums.

A great uncertainty exists about the maximum possible loss that may be caused by a hazardous waste risk. The criterion "maximum possible loss" would therefore probably not be satisfied unless the professional risk carrier introduced aggregate cover limits per client and per deposit. Moreover, it is sensible to give cover with more specific limitations in time, to introduce a high retention and to let the insured participate in the risk proportionately. All these measures inserted into the criterion "cover limits" reduce the risks of covering waste disposals for the professional risk carrier and may move them into his subjective domain of insurability. On the one hand these limitations reduce the coverage available to the insured from the private insurance industry below the optimal coverage that he may desire; on the other hand they increase the degree of insurability of hazardous waste risks and make more and more insurance capacity available for such risks.

Such measures could even fill substantial capacity gaps if they were accompanied by measures like

a) allowance for the waste producers to build tax-free reserves up to certain limits,

b) setting-up of hazardous waste risk pools, 
c) building up of increasing self-insured retentions by individual companies, preferably with the help of professional risk carriers,

d) making optimal use of the capacity available from a state fund,

e) making optimal use of the capacity of professional reinsurers and similar facilities.

\section{Exogenous components of hazardous waste risks which impede insurability and how to combat them}

When discussing endogenous components inherent in hazardous waste risks, we already met exogenous components, because the two categories are interwoven and it is difficult to draw a clear line between them. If, for example, as a consequence of the many years that gradually polluting waste disposals can be effective, it becomes difficult to determine the liable party or to distribute fairly the liabilities among involved parties, are these difficulties risk-inherent, i.e. endogenous, or are they exogenous since it is the task of courts or other "exogenous factors" to overcome these difficulties?

The following exogenous components that adversely affect the insurability of hazardous waste risks by letting them drift alongside critical dimensions of insurability out of the subjective domain of insurability for one professional risk carrier after another are in many cases a consequence of risk-inherent properties of waste disposal risks. We shall point out the critical criterion or criteria of insurability associated with an exogenous component that is impeding the insurability of hazardous waste risks and try to indicate how to combat or eliminate the component:

a) It is a natural expression of sympathy that court awards to a private person whose health may be badly impaired are generous. Such generosity, however, not only increases the critical criterion of insurance premium for insured waste producers, possibly to a level where insurance becomes too expensive for them, but it is also inconsistent with the critical criterion of public policy. It may leave later pollution victims with no compensation because of unavailability of insurance coverage at bearable terms and financial incapability of the accused waste producer to indemnify.

b) A legal system which encourages private persons to prefer charges against companies for damages for which they are not liable renders the critical criterion "moral hazard" unsatisfied for most professional risk carriers. Such a system that rewards dishonesty and pushes hazardous waste risks into the area of separation and further towards the objective domain of uninsurability should be changed no matter how good the intentions on which it was based originally may have been. Undesirable developments like the one described above cannot always be foreseen in advance. Cases like the Jackson Township where the financial recovery to residents of the municipality granted by the jury was based solely on worry, must be avoided in future. What a judicial system should aim at is that victims of pollution receive correct compensation from the responsible party (or its insurers). If the responsible party cannot be found, a state fund or funds to be set up by waste generating industries should provide for compensation.

c) As we have seen, the criteria "randomness", "public policy" and "insurance premium" may become unsatisfied due to the use of the same waste deposit by several waste producers. Due to the rule of joint and several liability imposed on generators, site owners, operators and transporters in the USA, "any party that handles or stores the waste is potentially liable for a substantial portion of the damage, no matter how careful the 
operation may be or how modern the equipment and methods" (5). This exogenous rule not only increases the fear of insurers to be used as "deep pockets" and drives the waste disposal used by many waste generators still further towards if not into the objective domain of uninsurability, but it also prevents serious clean-up operators, who are exposed to joint and several liability and can find no insurance coverage for their operations, from touching such hazardous waste sites.

Joint and several liability, that may have been set up with the good intention of securing compensation for every impaired person, actually turns ut in the long run to be inconsistent with public policy. It not only decreases the degree of insurability of many sites but also hampers cleanup operations and with it a better protection of the population from pollution.

In the USA "so far, only 23 of the 950 Superfund sites that the EPA says need immediate attention have ben cleaned up" (6).

d) Misinterpretations of the wordings of insurance contracts which favor plaintiffs are inconsistent with public policy and enhance moral hazard. They impede insurability, which may leave persons whose health is impaired later without any compensation, and they should be avoided. The most significant case in the USA in recent years involved Jackson Township in New Jersey, where the court interpreted "sudden and accidental" as "neither expected nor intended" (5).

e) Increasing sensitivity of the population to environmental impairment is certainly very welcome. A legal system should, however, not stimulate moral hazard. Since the party who is reponsible for damage should be liable for indemnification, and no one else, the burden of proof of connection between the cause (pollution) and the effect (harmful results to health) should be on the plaintiff's side. If no generator of the effect can be found, but an indemnification is very important, funds like the Superfund in the USA should be available.

f) In case of litigation between a waste producer and his insurers, the burden of proof should likewise be on the side of the waste producer, to avoid that the wrong insurer reimburses under covers for which he should not be liable. Since as a risk-inherent component the timing of hazardous waste liability damages may involve a multiple trigger, it is of utmost importance for the calculability of a hazardous waste risk premium that courts distribute liabilities on several insurers of waste damage as justly as possible. They contribute in such a way to satisfying the critical criterion "insurance premium" for some professional risk carriers. Furthermore, it is important that all courts follow the same criteria in the judgement of similar cases.

g) It is often extremely difficult to relate carcinogenicity to chemical waste (5). An interpretation that chemical waste is ultra-hazardous and an application of strict liability in accordance with the new toxic tort law, i.e. a determination that a chemical waste producer is liable for cancer of plaintiffs regardless of cause, would make the criterion of loss frequency critical and for most professional risk carriers even unsatisfied for chemical and other specific waste product risks.

An example of the danger of impeding insurability by application of strict liability is the case of United States vs. Waste Industries Inc. (7).

h) the criterion of maximum possible loss must become unsatisfied if a policy covers, for example, a polluting leak in a waste site as an occurrence and defines an upper limit to it but a court decides that each impaired or even only stressed individual who files a 
claim is to be treated as a claimant under a separate policy. In the Jackson Township case, over 300 persons were treated as claimants under separate policies. In this case, the insurers found the maximum possible loss to be more than 300 times as large as they had believed it to be (5). This case illustrates the importance of a very clear contract wording and the responsibility of a court to support and not undermine the insurability of hazardous waste risks.

i) Exogenous factors that could contribute to improve the insurability of hazardous waste risk are:

- improved research of waste hazards,

- intensive risk management,

- better definition of contract terms,

- stimulation by tax laws and authorities for "waste generators" to increase their retention by self-insured retention programs and to participate in special pools established to increase capacity for hazardous waste risks,

- cooperation of authorities with waste-producing industries, insurers and reinsurers to make enough capacity available for hazardous waste risks and to make optimal use of that capacity.

\section{REFERENCES}

(1) Hazardous Waste-Issues Surrounding Insurance Availability, Report to Congress by GAO, October 1987.

(2) B. Berliner - Gedanken zur Versicherbarkeit und zur Schiedsgerichtsklausel, Mannheimer Vorträge zur Versicherungswissenschaft, Heft 28, Verlag Versicherungswirtschaft, e.V., Karlsruhe, 1983.

(3) B. Berliner - Limits of Insurability of Risks, Prentice Hall, Inc., Englewood Cliffs, New Jersey 1982.

(4) B. Berliner and N. Buhlman - Subjective Determination of Limits of Insurability on the Grounds of Strategic Planning, The Geneva Papers on Risk Insurance, Vol. 11, No. 39, April 1986.

(5) H. Kunreuther, Problems and Issues of Environmental Liability Insurance, The Geneva Papers on Risk and Insurance, Vol. 12, No. 44, July 1987.

(6) Pollution / Insurer's proposal could cut EIL costs, Business Insurance, February 29, 1988. 